\title{
Sensibility and response keywords of users according to posting types of fashion Instagram Focused on Koreans' fashion brands
}

\author{
Youngjoo $\mathrm{Na}$ \\ Department of Clothing and Textiles, \\ Inha University, Incheon, The Republic of Korea, and \\ Jisu Kim \\ Inha University, Incheon, The Republic of Korea
}

Posting types of fashion

Instagram

Received 14 March 2018 Revised 26 March 2019 Accepted 29 March 2019

\begin{abstract}
Purpose - The purpose of this paper is to analyze the post type of the official account of the Korean fashion brands on Instagram and to analyze the images and keywords according to the use of the hashtag in it. This study also will provide data of how fashion brands use the new media of Instagram and how they promote it. Design/methodology/approach - This study investigated the types of postings and keywords of hashtag (\#) of fashion brand's official Instagram account in order to analyze the post type and keyword. In total, six apparel brand companies were selected, with two in each of three categories (classic casual brand, outdoor sports brand and designer character brand), and seven types of postings were classified (lookbook and product, collection, broadcasting ads, brand issue, sensibility pictures, sponsorship and event). The frequencies were collected according to their types that were confirmed by four fashion major specialists.

Findings - First, the proportion of the types of postings varied according to the characteristics of the brand. Second, the six brands used keywords of a symbol because it is important to convey brand identity. Third, the sensibility keywords of each brand were investigated, and one of the designer character brands used only practical keywords without sensibility keywords. Fourth, this study examined the number of Instagram hashtags and hearts to determine if the reaction was in alignment with the marketing trends of the company's official Instagram account and consumers. One of the classic casual brands, one of the outdoor sports brands and both designer character brands showed a high proportion of types of posts on Instagram that well matched with consumer response. As a hypothesis of this study, it was supported that the posting types of images and hashtags will be different according to the characteristics of brand.

Originality/value - Instagram is the fastest growing social network service (SNS) globally, especially among young adults. Instagram is noted for its strong SNS marketing but it has not been well researched in the apparel industry. The study results will help improve the brand image and promotion by using official Instagram account in the apparel industry.
\end{abstract}

Keywords SNS, Fashion brand, Sensibility

Paper type Research paper

\section{Introduction}

Recently, social media outlets such as Instagram, Facebook, Twitter and YouTube constitute excellent sources for developing relationships with customers. One specific way to do this is to create brand fan pages on social networking services (SNS). Companies can place a notice with regard to brand posts (containing photos, videos, messages,

(C) Youngjoo Na and Jisu Kim. Published by Emerald Publishing Limited. This article is published under the Creative Commons Attribution (CC BY 4.0) licence. Anyone may reproduce, distribute, translate and create derivative works of this article (for both commercial and non-commercial purposes), subject to full attribution to the original publication and authors. The full terms of this licence may be seen at http://creativecommons.org/licences/by/4.0/legalcode

This research was supported by Inha university Grant (2018).

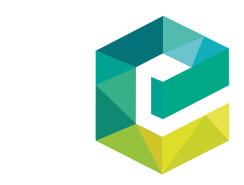

International Journal of Clothing Science and Technology Vol. 32 No. 1, 2020 Emerald Publing. 23-36 g Limited 0955-622

DOI 10.1108/IJCST-03-2018-0032 
IJCST

32,1

information, quizzes and other materials) on these brand fan pages. Customers can become fans of these brand fan pages, and they can subsequently indicate that they like the brand post or can comment on it. This liking and commenting on brand posts reflects the brand post popularity. Among the numerous SNS, this study focuses on Instagram because it had more than 500 million users in June 2016. Instagram users have recently been increasing by approximately 100 million per year, and 300 million users use the service more than once a day, with a daily average of 95 million photos and images being uploaded (Instagram, 2016).

Instagram is a mobile app (iOS and Android) that enables users to instantly turn their mobile snapshots into visually appealing images, which are then shared with others on the network. Instagram has quickly emerged as a new SNS medium. It provides users with an instantaneous way to capture and share their life moments with friends through a series of filter-manipulated pictures and videos (Hu et al., 2014). In the early days of SNS, communication was focused on letter but after the introduction of Instagram, these communication methods were transferred to photos and video (Johansson and Eklöf Wallsbeck, 2014). Media power can easily be identified through the number of followers of celebrities. With the increasing number of Instagram subscribers, companies are scrambling to develop a marketing strategy via Instagram.

Research and observation are critically important in the fashion business (Fatma, 2006). Published research tells us that the increase in the value of the clothing market is offset against the considerable value for money offered by clothing over time (Ann, 2005). In particular, fashion brands have begun to effectively expose their product with photos and videos. Hence, fashion brands have instigated Instagram strategies and uploaded their lookbook, pictorial, picture of sponsorship, branding issues and so on. There are advantages because Instagram users can only see the fashion brand that users selected and the latest information, video and pictures of brand are easily accessed via a hashtag (Johansson and Eklöf Wallsbeck, 2014).

Instagram has expanded enormously via its "Like" button because Instagram users want to know the available method and different colors, sizes and prices of the products that they post. To gain additional information, comments are actively written in official Instagram account of fashion brands. Companies can thereby predict and analyze the changes of the market by the contents and they can immediately identify the consumer responses. As Instagram is used mainly by young people, brands targeted at the young generation have employed Instagram for marketing purposes such as branding. An analysis of the marketing strategies that are used on Instagram will provide more insight into practical implications for brands using SNS, especially Instagram, for marketing purposes.

The orientation that fashion companies want to convey to consumers is determined on the basis of the written keywords, as well as hashtag, photos and videos. This study identifies and measures Instagram as a marketing tool in the apparel industry, selects fashion brands (Classic casual brand, Outdoor sports brand and Designer character brand) that continually take advantage of the official Instagram account, and analyzes the specific types of postings. Research problems are as follows. First, the image-based brand was analyzed by the types of postings. Second, consumer responses to posting of fashion brands were investigated. Third, Types of uploaded posts related directly to the brand were analyzed. Fourth, sensibility keywords in hashtag of each fashion brand were investigated. Fifth, consumer responses to keywords of fashion brands were examined. The hypothesis of this study is that the posting type of image and hashtag will be different according to the characteristics of brand. The results of article will be presented to marketing strategy of Instagram in the apparel industry in order to suggest materials that are the cornerstone of the study in relation to Instagram, which has not been well researched in the fashion research areas. 


\section{Background}

\subsection{Social network service (SNS)}

SNS can be defined as an individual web page that enables online, human-relationship building by collecting useful information and sharing it with specific or unspecific people (Kwon and Wen, 2010). Ellison (2007) defines SNS as web-based services that allow individuals to construct a public or semi-public profile within a bounded system, to articulate a list of other users with whom they share a connection and to view and traverse their list of connections and those made by others within the system. Hence, SNS allows individuals to network for a These sites provide a public forum that enables the exchange of digital information, such as pictures, videos, text, blogs and hyperlinks between users with common interests, such as hobbies, work, school, family and friendship. Content is both provided by and consumed by the SNS members. Membership is free with access being granted after registering and completing an optional profile. SNS usually have privacy control settings built into the profile options, which enable users to choose who can view and add content to their personal web pages.

The rapid growth in SNS membership has attracted advertising and marketing interest from companies looking for increased Internet exposure with consumers and for ways to improve brand loyalty. Most SNS service providers rely on online advertising to generate revenue. Advertisers are hoping that users of these sites will purchase their products, post favorable remarks about their products on their web page and those of their associates, and provide them with useful information about trends and products. SNS providers rely on increasing network externalities for economies of scale to propagate their business model (Sledgianowski and Kulviwat, 2009). One way to realize this aim is to create brand communities in the form of brand fan pages on SNS wherein customers can interact with a company by liking or commenting on brand posts (De Vries et al., 2012). Consumers who become fans of these brand fan pages tend to be loyal and committed to the company, and they are more open to receive information about the brand (Bagozzi and Dholakia, 2006). Moreover, brand fans tend to visit the store more, generate more positive word of mouth, and are more emotionally attached to the brand than non-brand fans (Dholakia and Durham, 2010). Nowadays, consumers are shopping with SNS, and consumer tastes and IT involvement explain their characteristics (Kim et al., 2017). Simple sales strategies that match the characteristics of consumers in the past are now showing limitations. Each brand is transformed from rational marketing to emotional marketing, driving customers to appeal to their sensibility.

\subsection{Instagram}

Instagram is an American company founded in 2010, and Instagram is a mobile application for smartphones, available on App Store and Google Play free of charge. Instagram, a portmanteau word of Instamatic and telegram, is a popular SNS developed for smartphones and other mobile devices that allows users to share photographs and short videos. On June 20, 2013, Instagram added the capability to post short videos. Instagram is dedicated to the mobile experience, and part of its growth was fueled by the rapid adoption of smartphones with high-functioning cameras (Salomon, 2013). It allows users to take square-shaped photographs, similar in format to Kodak Instamatic photographs, rather than the more typical 3:4 aspect ratio of most smartphone images. The images can be shared on other SNS as well, including Twitter, Facebook, Tumblr, Flickr, and Foursquare. It also allows users to apply a variety of photographic filters that alter the shading, temperature, feel, and presentation of the images. Users can also add a short description to their photographs before posting them online (Gibbs et al., 2015).

Instagram is simply constructed and it consists of five main buttons. Above all, to be able to use Instagram, the user needs to create an account and then can follow other users and be followed back. When a user follows another user's account, user's photos will appear on the homepage. The user can like or comment on other user's photos and by liking the photo, 
IJCST

32,1

26

the user shows that he/she admires the post. The most liked photos can be seen under the explore page. The explore page can also be used to search for other users or hashtags. On the activities page, the user can see recent activities, if the user has a new follower or if someone has commented or liked the user's photos. On the share page, the user can share a picture taken with the help of the mobile camera and he/she can then enhance the photo with the help of pre-modified filters. The user can also add a caption or hashtags to the photo. Hashtags categorize the photo with other photos with the same hashtag. Another option is to geotag the icon to the photo and thereby share the location of the place where photo was taken; the photo will then be categorized based on that specific location (Hassan, 2014).

The rapid uptake of Instagram as a marketing platform by the world's most popular brands, combined with the potential marketing and branding implications that it can have for individuals and organizations, merits further exploration of this visual social media platform. As noted earlier, many global brands have also begun to utilize this visual platform (Geurin-Eagleman and Burch, 2016). Miles (2013) identified three advantages that Instagram provides for utilization as a brand awareness tool. First, it is the only major SNS application that was launched on mobile phones rather than the Internet. Second, it is what Miles (2013) termed "social media lite," meaning that it is not conversation intensive such as Facebook and Twitter. Finally, content posted on Instagram is thought to have a longer shelf life than that of other SNS (Miles, 2013). The company can present a more personal picture of its brand, and by doing so the company conveys a more honest picture of itself through Instagram. The idea of Instagram pictures lies on on-the-go, a sense that the event is happening right now, and that adds another layer to the personal and honest picture of the company (Hassan, 2014).

"Victoria's Secret" is an example of Instagram marketing by a representative fashion company. This famous brand sells goods aimed at women's lifestyles and it has the largest number of followers among women's lifestyle brands. It uploads photos of fashion shows models and a variety of brand images, and even posts phrases. They promote the brand to followers and share them with the hashtag(\#) that follower purchase. By applying a filter provided by Instagram, the brand contents exert a loving and wonderful feeling that can be seen as the personality of the brand.

\subsection{Hashtag}

Instagram provides the opportunity for companies to reflect a picture of the brand through the eyes of the customers, using hashtag encouragement. Hashtags are central to organizing information on Twitter, Facebook, Instagram, and Flickr. Designated by a "hash" symbol (\#), a hashtag is a keyword assigned to information that describes SNS in searching (Small, 2011). Hashtags capture the ever-changing distribution of user interests: new hashtags that have never occurred before are constantly being created in response to recent events, products or newly famous people, some of which can become popular very quickly. Although users have particular biases of the kinds of images they upload, they also have biases of the kinds of hashtags they choose to write (Denton et al., 2015).

When a hashtag is used by many people from all over the world, it can be listed in the trending topics. As a hashtag becomes popular among people, it can achieve a rank in the trending topic list (Page, 2012). Therefore, hashtags can allow marketers to identify SNS conversations relevant to their business and to find their target groups in an efficient and effective manner. The use of hashtags has brought convenience to SNS users in various ways. As a user-defined index term of content, a hashtag links relevant topics and events together, making it much easier to assess a posting. For example, postings related to fashion are easily retrieved by a single click on the hashtag \#fashion. To this end, a hashtag acts as a social bookmark: annotating the content, being shared with other users, and assembling the folksonomy.

Sociologists, media observers and computer scientists have all noticed that hashtags have another role. Beyond a bookmark of content, a hashtag serves as the symbol of a community. 
Indeed, a hashtag enables users to identify and participate in online chats designated by the tag. Birds of a feather can be easily found and connected by tracking a particular hashtag. To this end, a hashtag defines a virtual community of users with the same background, the same interest, or involved in the same conversation or task. A user joins such a community by simply including that hashtag in his/her own tweets. The observations above have clearly indicated a critical hypothesis that while posting a hashtag, SNS users are aware of the dual role it plays - as a unique indicator of both the topic of the content and the membership of a community. In other words, by creating a hashtag, a user both invents and shares a new bookmark (of content), and initializes and spreads a coat of arms (of a community), or both. By adopting an existing hashtag, a user either presents his/her interest in a topic or presents his/ her intent to obtain a community membership, or both.

Indeed, in the existing literature, hashtags have been effectively utilized as critical features for various tasks of text or social network analysis, including topic detection and tracking, text classification, community identification, and link prediction. On the one hand, hashtags do perform effectively in most of these tasks as a specific types of features. On the other hand, because of the lack of a formal conclusion on the role of hashtags, it is difficult to explain why the involvement of hashtags works in some tasks but not in others (Yang et al., 2012). Wishpond (2014) noted the most popular hashtag content that contains brand hashtag, campaign hashtag and contents hashtag.

\section{Research method}

\subsection{Research method and targets}

To analyze the post type and keyword of Instagram, fashion brands were selected - six South Korean brands were chosen. Classic casual brands (B and $\mathrm{H}$ brands), outdoor sports brands ( $\mathrm{K}$ and $\mathrm{E}$ brands) and designer character brands ( $\mathrm{S}$ and $\mathrm{L}$ brands) were selected as targets. The standard of selection was the official fashion Instagram account that is composed of the Korean brand, an active account that should be uploaded at least three times a week, with frequently used hashtags. On average, B brand (about 5-6 of the week), $\mathrm{H}$ brand (about 7-8 of the week) and $\mathrm{K}$ brand (about 3-5 of the week), E brand (about 15-20 of the week) S brand (about 5-6 of the week), and L brand (about 8-10 of the week) were actively running Instagram. In addition, the average number of hashtags per image was as follows: B brand (about 6), $\mathrm{H}$ brand (about 7.9), $\mathrm{K}$ brand (about 4.5), $\mathrm{E}$ brand (about 6), S brand (about 6.7) and L brand (about 2.4). Although the use of hash tags is different for each of the six brands, brands use hash tags in a variety of ways. The criterion for selecting the brand of the same character was that classic casual brand "B brand" and "H brand" were similar to the opening day and the upload period also for each part of conglomerate "C corp" and "L corp." Outdoor sports brand "K brand" and "E brand" had a similar launching time and used a variety of hashtags. Although a number of Instagram accounts of outdoor sports brands in Korea have been deactivated, both brands continue to upload a variety of contents. "S brand" was produced by S designer and "L brand" was launched by K designer. Both brands were created for the 20-30 s target; hence, their followers were many young people and they had a similar opening day and had been operating Instagram for a long time. The research range was six months from October 2015 to March 2016. The type of hashtag for the uploaded post in six fashion brands was classified and the results were analyzed.

\subsection{Classification of types of postings}

The types of uploaded posts and hashtags for each fashion brand account were classified, and Instagram post photos and hashtags were investigated and recorded for each type. This analysis was applied to six fashion brand's official Instagram accounts, and features that were common to a variety of posts, uploaded images based on content, were classified into
Posting types of fashion Instagram 
IJCST

32,1

\section{8}

seven types of postings. Figure 1 shows sample images $(1 \sim 7)$ that are classification of the types of postings from upper left to lower right:

(1) Lookbook and product photos: the content of posts is the seasonal lookbook and photo that shows a product of their brand.

(2) Collection photos: during fashion week, photos are uploaded, which include a variety of runways, models and backstages.

(3) Video and photos of broadcasting and magazine advertisement: contents are uploaded including pictorials published in the magazine and TV advertisements and videos.

(4) Brand issue: it includes cultural events of the brand such as party and concerts and collaboration and opening of new store.

(5) Sensibility pictures not directly related with the brand: sensibility pictures are uploaded, which are directly related to the brand such as a post on the weather, a special day (Christmas and New Year).

(6) Photos provided by the sponsors to celebrities: fashion brand companies give sponsorship to famous people such as artists or models in order to promote their products.

(7) Events utilizing Instagram account: many events ask Instagram users to leave a comment and share the posts and give a benefit to Instagram users in random drawings.

\section{Results and discussion}

4.1 Image-based brand analysis by types of postings

Uploaded images were analyzed based on classic casual brand, outdoor sports brand, designer character brand. Upload proportion of lookbook and product photos were the highest in the account of classic casual brand that included $\mathrm{B}$ and $\mathrm{H}$ brands. This appeared to indicate a higher utilization to mainly show lookbook concept of the season. The official account of the outdoor sports brand ( $\mathrm{K}$ and $\mathrm{E}$ brands) was the highest in order to inform the event and provide brand issues to the consumers in accordance with active brand characteristics. The official account of the designer character brand (S and L brands) was used for posting collections and sponsorship pictures that were not used in both classic

Figure 1.

Classification of types of postings
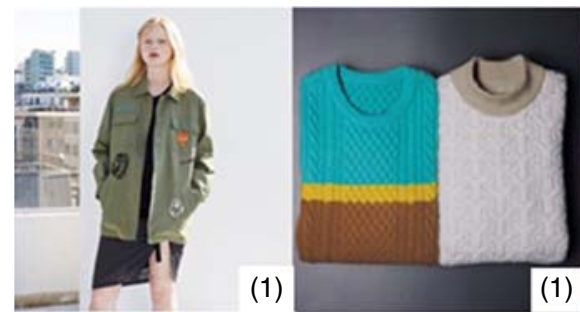

(1)
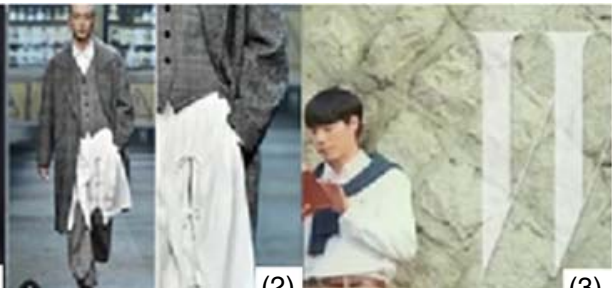

(2)

)

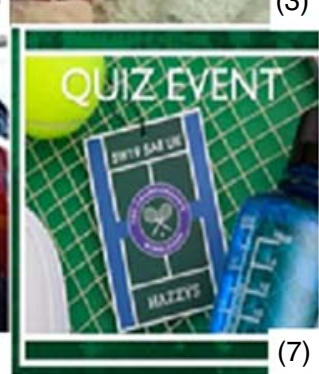

(5)

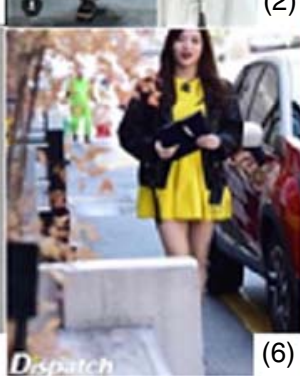

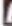

(6)
(3)
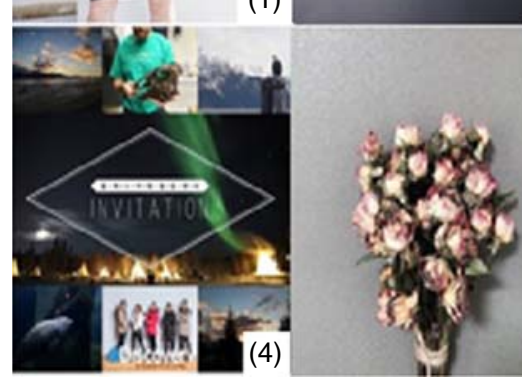
casual and outdoor sports brands. However, the posting of events associated with utilizing SNS was less than 10 percent in all the brands.

4.1.1 Classic casual brand. In classic casual brand, the number of types of postings (Table I) regarding lookbook and product photos was much higher compared to other types of postings. Fashion show did not upload photos because of not having a collection of classic casual brands. Also, no posts on the event with Instagram could be found, which means a lack of events marketing utilizing Instagram. Instagram pages for B brand utilized many images and video posts in the magazine and broadcast advertising and sensibility pictures. During the study period (June 2015-March 2016), H brand did not promote through magazines or broadcast $\mathrm{CF}$-associated images or videos. The biggest feature of $\mathrm{B}$ brand accounts was actively using the classic images of actors of popular dramas that reflected the trend. In addition, B brand tried to upload aggressive marketing as Instagram dramas made of advertisement of short stories. The official accounts of $\mathrm{H}$ brand uploaded images with many pastel colors, which can be seen as an account ID and the keyword "\#Hbrandlive," implying bright and vivid images. Lookbook posts occupied a large proportion utilizing the concept. The use on lookbook of models and actual artists in London strengthened the concept of the season and of England. This seems to be a recent trend of SNS that reflects global brands that communicate with consumers.

4.1.2 Outdoor sports brand. Outdoor sports brands commonly accounted for the highest proportion as E brand ( 36 percent) and $\mathrm{K}$ brand (61 percent). Due to the nature of the outdoor sports brand image, active male entertainers appeared in ad videos and photos that tended to show activity. E brand launched in 2012 is a Korean brand but it has an image associated with the professional documentary channel "Discovery" that shows outback exploration and challenge. Brand issues of $\mathrm{E}$ brand uploaded from news of expeditions to motion pictures can maintain and strengthen the image of the exploration and challenge. The lookbook and product photos of $\mathrm{K}$ brand accounted for the second highest proportion. Various uploads such as repetition of product photos and posts associated with other events were used to enhance the core product. In addition, the most prominent feature of the brand issue was saving wild animals containing a massive online and offline campaign. In connection with the campaign, utilization of the event using Instagram was the highest among six brands.

4.1.3 Designer character brand. Features account of designer character brands uploaded photos including photos of the fashion show runway and backstage during Fashion Week. Both brands barely used posts on sensibility pictures that were not directly related to the brand, and there was a lot of brand promotion and sponsorship via celebrity photos. On the contrary, the biggest difference was that the photos of collection of $\mathrm{L}$ brand were 7 percent, and $\mathrm{S}$ brand accounted for the highest rate of 45 percent among the types of postings, because S brand actively used a collection of live pictures utilizing the see now and buy now strategy over the study period (2015 June-2016 March). When uploading a picture of the product to the official account, $\mathrm{S}$ brand posted its products by expanding the features of the product and

\begin{tabular}{|c|c|c|c|c|c|c|c|}
\hline & B brand & $\mathrm{H}$ brand & $\mathrm{K}$ brand & E brand & $\mathrm{S}$ brand & L brand & \\
\hline Lookbook and product & 116 & 159 & 72 & 15 & 19 & 41 & \\
\hline Collection & - & - & - & - & 43 & 15 & \\
\hline Broadcasting ads & 70 & 0 & 34 & 52 & 11 & 9 & \\
\hline Brand issue & 29 & 28 & 324 & 57 & 9 & 44 & \\
\hline Sensibility pictures & 30 & 14 & 40 & 31 & 13 & 81 & Table I. \\
\hline Sponsorship & 10 & 6 & 17 & - & 1 & - & The number of \\
\hline Event & 6 & 6 & 43 & 3 & - & 18 & posting types \\
\hline Total & 261 & 214 & 530 & 158 & 96 & 208 & in brands \\
\hline
\end{tabular}

Posting types of fashion Instagram 
IJCST

32,1

30

uploading photos by type. The seasonal main items (fur, denim, glen check, etc.) were identified on Instagram, which means the brands use official Instagram like a second official homepage. Sponsorship with celebrities was the largest proportion for $\mathrm{L}$ brand and brand issues took second place, which showed a five-fold difference from S brand. As L brand stresses collaboration and a new second line, it was possible to quickly identify the direction of the major information of the brand.

4.1.4 Consumer responses on posting of fashion brand. Favorite postings ranked by number $1 \sim 3$ were found by the number of hearts (like) during the study period (Table II). This study found an association between a high proportion of types of postings with responses of consumers in the brand's official account. For B brand, events with the lowest posting were ranked first in consumer reaction because Instagram users click hearts in order to get new shirts. The second rank was achieved by Instagram drama and third rank by product photos that have the highest posting. Except event posting, broadcasting ads and product photos were associated with consumer reactions. Classic casual brand had the highest posting in lookbook and product photos and $\mathrm{H}$ brand also had highest the number of hearts in lookbook and product photos. Outdoor sports brand had the highest posting in brand issue and broadcasting ads and $\mathrm{K}$ brand also had the highest number of hearts in brand issue and broadcasting ads. When $\mathrm{K}$ brand was running brand's official Instagram account, the highest posting is associated with consumer reactions. E brand was ranked third in brand issues but appeared in lookbook (first rank) and event (second rank) because lookbook showed popular celebrities. Designer character brands used many photos of collection and sponsorship and S brand also showed photos of collection (first rank), lookbook (second rank) and sponsorship (third rank). L brand showed photos of sponsorship (first, second rank) and brand issue (third rank) that were all associated with consumer reactions.

\subsection{Keyword-based brand analysis by types of postings}

4.2.1 Classic casual brand. Figure 2 shows keywords of $\mathrm{B}$ and $\mathrm{H}$ brands, $\mathrm{B}$ brand sensibility keyword was 374 (23 percent) of hashtags (a total of 1591) and symbolizing brand such as "\#Bbrand," and "\#BbrandMan" was 287 (18 percent). H brand symbol keyword was 531 (31 percent) of hashtags (a total of 1700), kinds of product was 376 (22 percent) and sensibility

Table II.

Consumer responses to posting of fashion brands (like is the number of hearts)

\begin{tabular}{|c|c|c|c|}
\hline Fashion brand & First rank & Second rank & Third rank \\
\hline $\mathrm{B}$ brand & $\begin{array}{l}\text { Event } \\
\text { - providing new shirts } \\
\text { (like: } 1,720)\end{array}$ & $\begin{array}{l}\text { Broadcasting ads } \\
\text {-Instagram drama } \\
\text { (like: } 1,026)\end{array}$ & $\begin{array}{l}\text { Product photos } \\
\text {-down jacket } \\
\text { (like: } 158 \text { ) }\end{array}$ \\
\hline $\mathrm{H}$ brand & $\begin{array}{l}\text { Lookbook } \\
\text { - celebrity } \\
\text { (like: } 94 \text { ) }\end{array}$ & $\begin{array}{l}\text { Lookbook } \\
\text { - London season concept } \\
\text { (like: } 49 \text { ) }\end{array}$ & $\begin{array}{l}\text { Sponsorship } \\
\text { - celebrity } \\
\text { (like: } 44)\end{array}$ \\
\hline $\mathrm{K}$ brand & $\begin{array}{l}\text { Brand issue } \\
\text { - celebrity } \\
\text { (like: } 6,171 \text { ) }\end{array}$ & $\begin{array}{l}\text { Brand issue } \\
\text { - celebrity } \\
\text { (like: } 3,617 \text { ) }\end{array}$ & $\begin{array}{l}\text { Broadcasting ads } \\
\text { - celebrity } \\
\text { (like: } 2,299 \text { ) }\end{array}$ \\
\hline $\mathrm{E}$ brand & $\begin{array}{l}\text { Lookbook } \\
\text { - celebrity } \\
\text { (like: } 57 \text { ) }\end{array}$ & $\begin{array}{l}\text { Event } \\
\text { - providing down jacket } \\
\text { (like: } 218 \text { ) }\end{array}$ & $\begin{array}{l}\text { Brand issue } \\
\text { - Explore Iceland } \\
\text { (like: 156) }\end{array}$ \\
\hline $\mathrm{S}$ brand & $\begin{array}{l}\text { Collection } \\
-16 \mathrm{~s} / \mathrm{s} \\
\text { (like: } 1,319)\end{array}$ & $\begin{array}{l}\text { Lookbook } \\
-16 \mathrm{~s} / \mathrm{s} \\
\text { (like: } 919)\end{array}$ & $\begin{array}{l}\text { Sponsorship } \\
\text { - celebrity } \\
\text { (like: } 849 \text { ) }\end{array}$ \\
\hline $\mathrm{L}$ brand & $\begin{array}{l}\text { Sponsorship } \\
\text { - celebrity } \\
\text { (like: } 1,051 \text { ) }\end{array}$ & $\begin{array}{l}\text { Sponsorship } \\
\text { - celebrity } \\
\text { (like: } 886 \text { ) }\end{array}$ & $\begin{array}{l}\text { Brand issue } \\
\text {-launching of brand line } \\
\text { (like: } 698 \text { ) }\end{array}$ \\
\hline
\end{tabular}




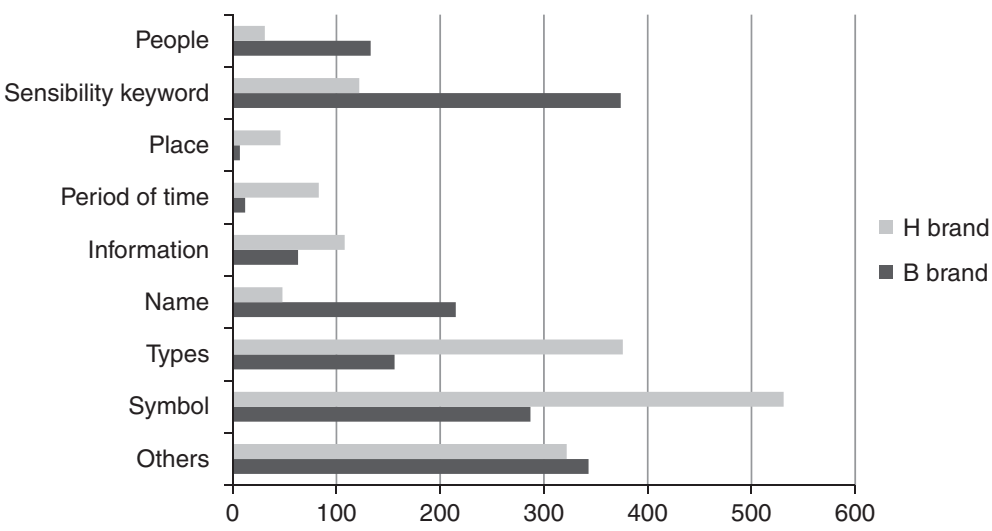

Posting types of fashion Instagram

keyword was 122 (7 percent). The most common words in both brands were brand name and when referring to the products, the product code was used instead of the product name. An apparel company in many kinds of seasonal clothes writes an accurate product description so that Instagram users can easily find the products. B brand used "\#classic" directly as the keyword in photos of lookbook and sponsorship that can be seen to define the image of itself as a classic. Hashtags that name the actor and sponsorship were associated with the drama, accounting for approximately 6 percent. $\mathrm{H}$ brand mentioned the names of various categories of product more than B brand and made the hashtags such as "\#Hbrandshoes," "\#Hbrandjacket," which indicated the brand name and types of products. Events in conjunction with artist collaboration in order to promote the brand were "\#artist name', \#H brand + artist name." For $\mathrm{H}$ brand, keywords related to people were sharply lower and the names of the celebrities who received sponsorship were fewer than 30. Hashtags used per posting for B brand were 6 and $\mathrm{H}$ brand were 7.9 , which used the most keywords of the six brands.

4.2.2 Outdoor sports brand. Figure 3 shows keywords of $\mathrm{K}$ and $\mathrm{E}$ brands, and symbol keywords accounted for the largest portion in both brands. Both brands have a long brand name, so K brand used "\#K brand" or "\#short name of $\mathrm{K}$ brand" and $\mathrm{E}$ brand used \#E brand' or "\#short name of $\mathrm{E}$ brand." Celebrities who were gaining popularity in China were models of $\mathrm{K}$ brand, so "\#K-style (Korea style)" was used together with brand names. K brand was consistently posting events and offline promotional scene in order to project its brand.

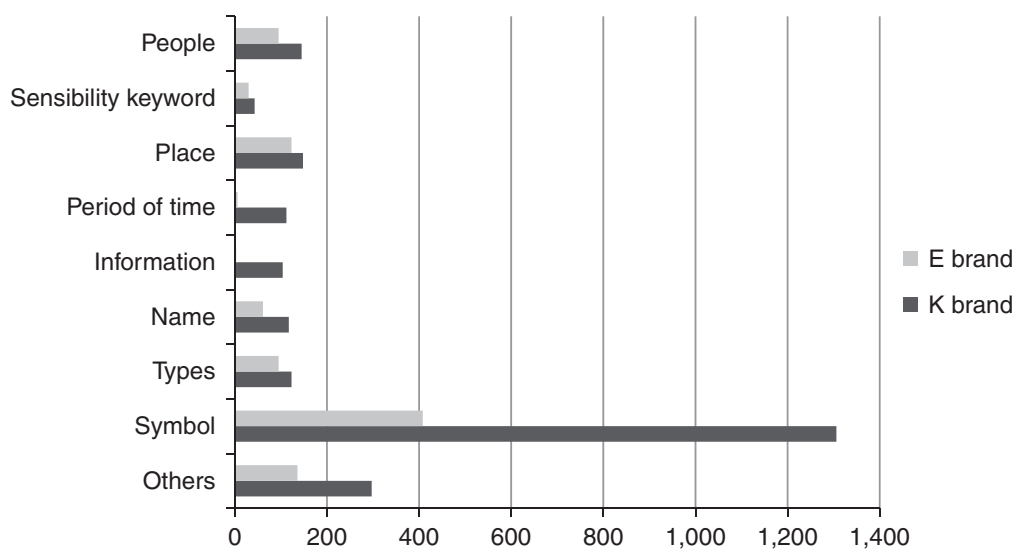

Figure 3.

Keywords of $\mathrm{K}$ and $\mathrm{E}$ brands

Keywords of $\mathrm{B}$ and $\mathrm{H}$ brands 
IJCST

32,1

32

Therefore, "\#Project full name" or "\#Project short name" accounted for 223 (10 percent). E brand made keyword \#"IAM + E brand," which represented a brand identity that highlights discovery and adventure. E brand uploaded lookbook, taken up mainly in Australia and Alaska, so the name of the country and city frequently appeared as keywords. The most used single keyword was "\#expedition" to represent ongoing events each year from E brand. E brand supported the journey of customers and uploaded their journeys on Instagram channel. Outdoor sports brand had easily understood main items, such as K brand, which uploaded "\#Project name" that was mentioned in lookbook, product photos, $\mathrm{CF}$ and brand issues. E brand uploaded "\#product name" or "\#New product name," which accounted for 90 percent of the product name keyword. Hashtags used per posting for K brand were 4.5 and for E brand were 6 .

4.2.3 Designer character brand. Figure 4 show keywords of S and L brands. In the case of $\mathrm{S}$ brand, first rank is that kinds of products are 104 (16 percent) and the second rank is that symbol is 91 (14 percent). On the contrary, as in L brand, the first rank is that symbol is 135 (26 percent) and the second rank is that the name of product is 93 (18 percent). S brand used only "\#short name of S brand" in a single keyword and only used English in all hashtags. S brand used many sensibility keywords as the second of the six brands used adjectives such as "\#attractive." This can be known as the status of the brand and image-forming step as a global designer brand using foreign model in lookbook and pictorial and hashtag in English. L brand used "\#L brand" as the keyword of a symbol and uploaded a steady hashtag called "\#my + L brand," which conveyed brand affection and ownership to consumers. S brand used only product type with a hashtag instead of the product name. L brand appeared as the overwhelming number of people (10 percent) in six brands, and most of the figures keyword appeared in photos of brand issues and sponsorship. A person wearing $\mathrm{L}$ brand also showed the product name rather than the type of product. This emphasized the difference between the brand identity and universal keywords. Both brands uploaded celebrities wearing clothing collections instead of popular celebrities as advertisement models. Further, because the collection in progress SS/FW season was unlike the four brands, videos and photos of fashion shows appeared with "\#SFW (Seoul Fashion Week)" and "\#2016SS" related collection. Hashtags used per posting were 6.7 for S brand and 2.4 for L brand. L brand used a variety of videos and photos and ran as an image-based brand on Instagram rather than keywords.

4.2.4 Analysis of sensibility keyword in hashtag of each fashion brand. Sensibility keywords of hashtags were investigated in each brand (Table III); B brand and $\mathrm{H}$ brands had the largest number of sensibility keywords such as "\#classic," which indicated the mood of the brand. B brand posted photos with "\#advanced/contemporary," "\#essential"

Figure 4.

Keywords of $\mathrm{S}$ and $\mathrm{L}$ brands

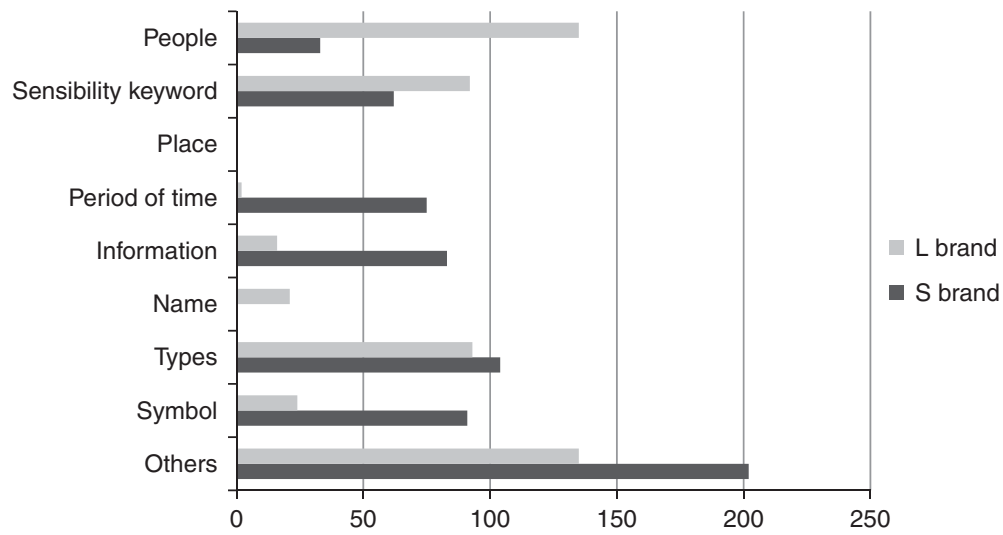


and $\mathrm{H}$ brand posted lookbook and photos of products with \#essential' and "\#Cool." $\mathrm{K}$ brand used many keywords as "\#Daily life" to highlight the items that can be worn in daily life. Keywords of "\#Nature," "\#Touching" ranked second and third in the pictorial and brand issues. E brand used "\#travel," "\#camping" and "\#road Trip," showing the characteristics of outdoor sports brand. The brand slogan of E brand was "Our world is full of fun" and "I am a discoverer," which are similar to keywords such as "\#expedition," "\#discovery" and "\#challenge." S brand repeatedly posted "\#naughty" and "\#young \& classic" associated with the concept of the season and repeatedly reinforced the concept. S brand emphasized personality by expressing emotions "\#feellikeflying" befitting the image of a character designer brand. L brand used only practical keywords related to the product name and people and sensibility keywords could not be found.

4.2.5 Consumer responses to keyword of fashion brand. To examine the similarity of keywords between consumer behavior and fashion brand, this study investigated the hashtags of Instagram of official brand and user Instagram account that uploaded the brand-related posting (Table IV). User Instagram account based on the keywords obtained from the official account was ranked, including similar search words and related search words by utilizing the search function of Instagram hashtag. Instagram exhibited a similar pattern of keywords and the most common keyword was brand name. User Instagram account uploaded hashtags of the types of products and brand issue because Instagram users want to participate in events to get promotion goods. User Instagram account used a wide range of keywords than official account but these keywords were flooded with postings not related to the brand. Therefore, it is uncertain if consumers posting brand-related content used these keywords to use the brand.

\begin{tabular}{llll}
\hline Fashion brand & First rank & Second rank & Third rank \\
\hline B brand & Classic(16) & Advanced/Contemporary(14) & Essential(5) \\
H brand & Classic(5) & Essential(3) & Cool(2) \\
K brand & Daily Life(21) & Nature/Kinfolk(6) & Touching(3) \\
E brand & Travel(15) & Camping/Road trip(7) & Expedition/Discovery/Challenge(2) \\
S brand & Young \& Classic(30) & Naughty(10) & FeelLikeFlying(9) \\
L brand & - & - & - \\
\hline
\end{tabular}

Posting types of fashion Instagram

\begin{tabular}{lll}
\hline Fashion brand & Account & \#hashtag keyword(the number of hashtags) \\
\hline \multirow{2}{*}{ B brand } & User Instagram & \#B.N. (38,646), \#B.N. accessory(2,346), \#B.N. shirts(100) \\
& Official Instagram & \#B.N.(228), \#model celebrity name(69), \#CLASSIC(48) \\
H brand & User Instagram & \#B.N.(15,682), \#B.N. accessory(3,425), \#B.N. IN PETERLAND(256) \\
& Official Instagram & \#B.N. (209), \#B.N. LADIES(99), \#B.N.S LIVE(89) \\
K brand & User Instagram & \#B.N. \& B.N. SPORTS(25,956), \#B. campaign name: Penguin Fly \\
& & (4782), \#B. slogan: Love Your Foot(1,490) \\
& Official Instagram & \#B.N. \& B.N. SPORTS (587), \#OUTDOORGRAM(257), \#campaign \\
& name: Penguin Fly (200) \\
& User Instagram & \#B.N.(18,800), \#B.N. short name(289), \#product name(123) \\
& Official Instagram & \#B.N.(253), \#I AM B.N.er (114), \# product name (37) \\
S brand & \#ser Instagram & \# B.N.(8628), \# B.N. short name (1525) \#B.N. COLLECTON (36) \\
& Official Instagram & \#B.N. short name (78), \#2016 S/S (48), \#B.N. COLLECTION (42) \\
L brand & User Instagram & \#B.N.(48,142), \#MY B.N.(2183) \#B.N. product name(415) \\
& Official Instagram & \#B.N.(74), \#MY B.N.(50), \#B.N. logocap(21)
\end{tabular}

Note: BN, brand name
Table IV.

Consumer responses to keyword of fashion brands 
IJCST

32,1

\section{Conclusions}

In the fashion market, Instagram has a huge impact and many companies are marketing through Instagram. For companies in the fashion industry, Instagram is being used as a channel for communication with many consumers. This study investigated the type of posting and hashtag (\#) of fashion official account on Instagram by analyzing the images and keywords in order to determine the message and marketing tendency of the brands. Basic data were provided, which might be useful when developing a marketing strategy through the official Instagram account of the apparel industry.

The study results are as follows. First, the proportion of types of posting differed according to the nature of the brand. Classic casual brands uploaded the most postings in lookbook, and product photos and outdoor sports brands uploaded the most postings in brand issue and broadcasting ads. Designer character brands uploaded many photos of collection and sponsorship not using classic and outdoor sports brands. However, the characteristics differed between each of the two related brands because of the difference of utilization from SNS marketing and brand identity.

Second, the official account of the six fashion brands used a total of seven hashtags that were classified into nine types. Outdoor sports brand " $K$ brand" used the most hashtags that was 1.5 times more than $\mathrm{H}$ brand, ranking second for using hashtag. It showed that using a symbol is the most common keywords in the six brands because it is important to convey brand identity. Similar fashion brands frequently used similar hashtags, for example, the most common words appearing in the classic fashion brands were the brand name. When referring to the products, product codes were used instead of product name to make it easier for Instagram users to find the products. Outdoor sports brands had long brand names when uploading a symbol of keywords to make a variety of keywords, such as "\#I am + brand name" showed the brand identity, and both brands utilized hashtags for celebrities who were hired as advertising models. Designer character brands utilized keywords containing the brand personality and S brand marked all the hashtags only in "English" so as to become a global brand. L brand exhibited the overwhelming number of names of people among the six brands that showed keywords in the photos of sponsorship and brand issue. Hashtags per posting (2.4) was the fewest among the six brands because of the image-based operating Instagram.

Third, the sensibility keywords of each brand were investigated by classifying a hashtag depending on the nature of keywords. All classic casual brands directly used "\#classic" as a keyword in order to define the image of itself as classic. K brand highlighted the items that can be worn in everyday life, using the keyword "\#daily life." E brand used "\#travel" and "\#camping" exposed with pictorial and lookbook and conveyed active keywords as "\#expedition," "\#discovery" and "\#challenge," which were similar to its brand slogan. S brand repeated the keywords associated with the brand concept and emphasized the use of sensibility keywords to directly express emotions. On the contrary, L brand used only practical keywords instead of sensibility keywords.

Fourth, the number of Instagram hashtags and hearts was examined to determine if the reaction met the marketing trends of the company's official Instagram account and consumers. $\mathrm{H}$ brand in classic casual brand, $\mathrm{K}$ brand in outdoor sports brand and both brands in designer character brands showed a high proportion of types of posts on Instagram that well matched with consumer response. B brand had the fewest uploading events but had ranked first in the number of hearts (consumer response). Companies with the most underused event postings need to increase the number of postings in consideration of the consumers' response. E brand had a higher reaction of consumers about event and lookbook than the postings of brand issue and broadcasting ads that the company focused on. Therefore, it should be complemented by a thorough analysis of the marketing direction for the official account. Major keywords of official Instagram showed many brand names and promotions that revealed a similar pattern between 
official Instagram and user Instagram. Official Instagram subdivided the keywords and utilized more keywords but user Instagram did not identify.

Marketers in fashion-related fields improve communication with customers for effective design of products and better marketing. As a hypothesis of this study, it was supported that the posting types of images and hashtags were different according to the characteristics of the brand. Based on these results, companies should refer to three different types of brands and three analysis results of representative model, such as Classic casual brand, Outdoor sports brand and Designer character brand. It is important to keep in mind the operation of the official Instagram account by the use of appropriate hashtag marketing for the identity and by proper posting to help promote the brand and enhance brand image.

\section{References}

Ann, P. (2005), "Uniformity and differentiation in fashion", International Journal of Clothing Science and Technology, Vol. 17 No. 3, pp. 253-263.

Bagozzi, R.P. and Dholakia, U.M. (2006), "Antecedents and purchase consequences of customer participation in small group brand communities", International Journal of Research in Marketing, Vol. 23 No. 1, pp. 45-61.

Denton, E., Weston, J., Paluri, M., Bourdev, L. and Fergus, R. (2015), "User conditional hashtag prediction for images", Proceedings of the 21th ACM SIGKDD International Conference on Knowledge Discovery and Data Mining, pp. 1731-1740.

De Vries, L., Gensler, S. and Leeflang, P.S. (2012), "Popularity of brand posts on brand fan pages: an investigation of the effects of social media marketing", Journal of Interactive Marketing, Vol. 26 No. 2, pp. 83-91.

Dholakia, U.M. and Durham, E. (2010), “One Café Chain's Facebook experiment”, Harvard Business Review, Vol. 88 No. 3, p. 26.

Ellison, N.B. (2007), "Social network sites: definition, history, and scholarship", Journal of Computer-Mediated Communication, Vol. 13 No. 1, pp. 210-230.

Fatma, M. (2006), "The creative role of sources of inspiration in clothing design", International Journal of Clothing Science and Technology, Vol. 18 No. 4, pp. 278-293.

Geurin-Eagleman, A.N. and Burch, L.M. (2016), "Communicating via photographs: a gendered analysis of Olympic Athletes' visual self-presentation on Instagram”, Sport Management Review, Vol. 19 No. 2, pp. 133-145.

Gibbs, M., Meese, J., Arnold, M., Nansen, B. and Carter, M. (2015), “\#Funeral and Instagram: death, social media, and platform vernacular", Information, Communication \& Society, Vol. 18 No. 3, pp. 255-268.

Hassan, A. (2014), "Do brands targeting women use instamarketing differently: a content analysis", Marketing Management Association Spring 2014 Proceedings, pp. 62-65.

Hu, Y., Manikonda, L. and Kambhampati, S. (2014), "What we instagram: a first analysis of Instagram photo content and user types", Proceedings of the Eighth International AAAI Conference on Weblogs and Social Media, pp. 595-598.

Instagram (2016), "Year in review: 2016 in numbers", available at: http://blog.Instagram.com (accessed August 25, 2016).

Johansson, U. and Eklöf Wallsbeck, F. (2014), "Instagram marketing: when brands want to reach generation y with their communication", Halmstad University Bachelor thesis, Halmstad.

Kim, J., Jin, J., Hyun, H. and Na, Y. (2017), "Consumer response change according to the level of personalization of internet shopping mall", Science of Emotion and Sensibility, Vol. 20 No. 2, pp. 59-72.

Kwon, O. and Wen, Y. (2010), "An empirical study of the factors affecting social network service use”, Computers in Human Behavior, Vol. 26 No. 2, pp. 254-263. 
IJCST

32,1
Miles, J.G. (2013), Instagram Power: Build your Brand and Reach More Customers with the Power of Pictures, McGraw-Hill, New York, NY, pp. 211-213.

Page, M. (2012), "The linguistics of self-branding and micro-celebrity in Twitter: the role of hashtags", Discourse \& Communication, Vol. 6 No. 2, pp. 181-201.

Salomon, D. (2013), "Moving on from Facebook using Instagram to connect with undergraduates and engage in teaching and learning", College \& Research Libraries News, Vol. 74 No. 8, pp. 408-412.

Sledgianowski, D. and Kulviwat, S. (2009), "Using social network sites: the effects of playfulness, critical mass and trust in a hedonic context", Journal of Computer Information Systems, Vol. 49 No. 4, pp. 74-83.

Small, T.A. (2011), "What the hashtag? 'a content analysis of Canadian politics on Twitter. Information'”, Communication \& Society, Vol. 14 No. 6, pp. 872-895.

Wishpond (2014), "3 Key hashtag strategies: how to market your business \& content", available at: http://blog.wishpond.com/post/62253333766/3-key-hashtag-strategies-how-to-market-your (accessed August 25, 2016).

Yang, L., Sun, T., Zhang, M. and Mei, Q. (2012), "We know what@ you\# tag: does the dual role affect hashtag adoption?", Proceedings of the 21st International Conference on World Wide Web, pp. 261-270.

\section{Corresponding author}

Youngjoo Na can be contacted at: youngjoo@inha.ac.kr

For instructions on how to order reprints of this article, please visit our website: 